\title{
Ética e corporações: tensões entre interesse público e privado
}

\section{Gilberto Dupas}

- Especialista em Administração pela University of Western Ontario, Canadá; em Economia Matemática e Econometria pela Cepal (Comissão Econômica para a América Latina e o Caribe)//pea (Instituto de Pesquisa Econômica Aplicada), Brasil; em Economia pela Pontifícia Universidade Católica do Rio Grande do Sul (PUC-RS), Brasil; e em Política de Negócios pela Universidade de São Paulo, Brasil/Delft University, Holanda

- Graduado em Engenharia de Produção pela USP

- Professor visitante da Universidade Paris II e da Universidade Nacional de Córdoba

- Autor de vários livros, entre eles Economia global e exclusão social, Ética e poder na sociedade da informação, Hegemonia, estado e governabilidade, Tensões contemporâneas entre o público e o privado, Renda, consumo e crescimento, Atores e poderes na nova ordem global e 0 mito do progresso

- Foi membro do Conselho Nacional de Avaliação do Ensino Superior (Conaes) do Ministério da Educação e Cultura; do Conselho Deliberativo do Instituto de Estudos Avançados da USP; do Conselho do Cebrap; do Conselho Diretor da Fundação Getúlio Vargas (FGV) e de seu Comitê de Planejamento Estratégico

- Foi Secretário de Estado de Agricultura e Abastecimento de São Paulo e presidente da Caixa Econômica do Estado

- Coordenador geral do Grupo de Conjuntura Internacional (Gacint) - USP

- Presidente do Instituto de Estudos Econômicos e Internacionais (IEEI)

- Editor da revista Política Externa

-gdupas@uol.com.br 


\section{Resumo}

A questão da ética nas grandes corporações está essencialmente ligada ao imenso poder que elas adquirem na atual lógica global, definindo os produtos a serem consumidos e a maneira de produzi-los em escala mundial. Em decorrência disso, elas ficam continuamente expostas a questões sociais críticas advindas de suas decisões, como responsabilidades na degradação ambiental, produtos nocivos na alimentação, desemprego, crescimento da informalidade e propaganda enganosa.

PALAVRAS-CHAVE: ÉTICA • GRANDES CORPORAÇÕES • GLOBALIZAÇÃO • RESPONSABILIDADE SOCIAL DAS EMPRESAS

• TECNOLOGIAS DA INFORMAÇÃO • TENSÕES ENTRE PÚBLICO E PRIVADO • HEGEMONIA DO CAPITAL

Abstract

The question of ethics in major corporations is basically related to the immense power that they acquire within current global logic, defining the products to be consumed and the way to produce them on a worldwide scale. As a result of this, they are continually exposed to critical social issues that stem from their decisions, like responsibility for environmental degradation, harmful products in food, unemployment, growing informality and deceitful advertising.

KEYWORDS: ETHICS • MAJOR CORPORATIONS • GLOBALIZATION • SOCIAL RESPONSIBILITY OF THE COMPANIES •

INFORMATION TECHNOLOGIES • TENSIONS BETWEEN PUBLIC AND PRIVATE・HEGEMONY OF CAPITAL

\section{Resumem}

La cuestión de la ética en las grandes corporaciones está esencialmente ligada al inmenso poder que éstas adquieren en la actual lógica global, ya que definen qué productos se consumirán, así como los modos de consumo. Estas organizaciones permanecen expuestas a cuestiones sociales críticas, debido a sus decisiones, tales como: responsabilidades en la degradación ambiental, productos nocivos en la alimentación, desempleo, crecimiento de la informalidad y propaganda engañosa.

PALABRAS CLAVE: ÉTICA • GRANDES CORPORACIONES • GLOBALIZACIÓN • RESPONSABILIDAD SOCIAL DE LAS EM-

PRESAS • TECNOLOGÍAS DE LA INFORMACIÓN • TENSIONES ENTRE LO PÚBLICO Y LO PRIVADO • HEGEMONÍA DEL

CAPITAL 
$\bigvee_{\mathrm{p}}^{\mathrm{a}}$ amos analisar aqui a ética das corporações tendo como base as tensões contemporâneas entre interesse público e privado. O poder escapa progressivamente do espaço público, porque suas instituições políticas tradicionais estão se incapacitando a fornecer segurança e garantias a seus cidadãos. Isso leva à crescente polarização social e a um ambiente de medo difuso e insegurança geral que não favorece a articulação de uma ação coletiva. Os serviços públicos básicos se deterioram, os serviços privados se impõem, esvai-se o espaço de igualdade dos cidadãos em torno das instituições públicas e agravam-se as tensões entre público e privado. O recuo das políticas públicas acirra o desejo dos governos de empurrar para o âmbito privado responsabilidades sociais e os destinos da desigualdade, levando as grandes empresas a descobrirem que esse novo espaço pode render altos dividendos de imagem pública e social. São esses os temas que este ensaio busca tratar. Inicialmente abordaremos os conflitos e ambigüidades presentes no uso dos termos público e privado; em seguida, trataremos da ascensão do capital em contraposição à diluição e fragmentação do espaço público, com os conflitos decorrentes. Finalmente, abordaremos as formas pelas quais o capital busca por legitimidade, principalmente pela incorporação do conceito de "responsabilidade social” das empresas.

\section{Contradições entre público e privado}

Ambigüidades semânticas são inerentes ao uso dos termos público e privado, revelando suas dimensões contraditórias e multidimensionais. Numa primeira abordagem, o interesse público pode ser entendido numa relação antagonista tanto com o interesse do indivíduo - ou grupo de indivíduos com demandas específicas - como com o interesse da empresa. Estes dois últimos, definidos como pertencentes ao campo do interesse privado, são necessariamente particularistas e, embora possam compor a teia de influências que definem o interesse público, não têm como pretender representar o interesse geral. Há, no entanto, uma outra abordagem que nos convém acentuar. Nela, o privado aparece como o direito do indivíduo à privacidade. Nesse caso, o antagonista tanto pode ser o Estado autoritário ou excessivamente regulador como a corporação criadora e manipuladora dos desejos de consumo e das mídias globais. Estado e empresas também podem aparecer numa relação antagonista ao indivíduo, entendido como cidadão privado, quando o Estado é indiferente em relação aos efeitos sociais sobre o cidadão das políticas econômicas que aplica; ou a empresa quando, por exemplo, desenvolve tecnologias que geram desemprego estrutural ou degradação ambiental.

Em busca do mapeamento de limites entre o privado e o público, é necessário articular dialeticamente no mínimo dois níveis na análise: a ação do indivíduo e a estrutura coletiva na qual essa ação se inscreve. Trata-se de explorar as distinções entre razões do individuo e das empresas e razões do Estado; entre ética individual e ética de grupo; ou ainda, numa linguagem weberiana, entre ética da convicção e ética da responsabilidade ${ }^{1}$.

1 Segundo Max Weber, a ética da convicção refere-se ao conjunto de normas e valores que orientam o comportamento na esfera privada. Já a ética de responsabilidade representa esse mesmo conjunto de normas e valores quando orientam a decisão do político com base em sua posição como governante ou legislador. 
O exercício da liberdade pode significar tanto a faculdade de praticar ou não certas ações, como a autonomia para não obedecer a normas que setores hegemônicos ${ }^{2} \mathrm{da}$ sociedade tentam impor.

\section{A fragmentação do espaço público e a ascensão hegemônica do capital}

A consolidação do capitalismo global do pós-guerra fria definiu claramente o tom hegemônico contemporâneo. A mobilidade dos capitais e a emergência de um mercado metanacional criaram uma nova elite que controla os fluxos produtivos, financeiros e das informações, atuando predominantemente em redes e reduzindo progressivamente seus vínculos com suas comunidades de origem. Em consequiência, enquanto o mercado internacional se unifica, a autoridade estatal se enfraquece. Com isso, acentua-se a fragmentação, ressurgem os nacionalismos e os tribalismos e acelera-se a perda do monopólio legítimo da violência pelo Estado, que agora compete também com grupos armados e com o crime organizado em vários lugares do globo.

Na pós-modernidade, a ordem social implica a superação de uma dinâmica de oposição de classes pela criação de uma nova estrutura de castas: de um lado, os incluídos; de outro, os excluídos de todos os tipos. A nova classe dirigente tem uma clara visão tecnocrática e funcional sobre as orientações políticas e econômicas. Com crescente influência das lógicas organizacionais, o processo de dessimbolização do mundo ${ }^{3}$ passa a ter o economicismo e o tecnocratismo como referências centrais. A crise da civilidade e a intensificação do narcisismo levam o indivíduo a uma emancipação de todo o enquadramento normativo e a uma aversão à esfera pública, pois a liberdade passa a ser percebida como possível unicamente na esfera privada, o que gera a progressiva privatização da cidadania. Por outro lado, agora neste mundo totalmente estruturado em redes pelas tecnologias da informação, a vida social contemporânea passa a ser composta por uma infinidade de encontros e conexões temporárias. O projeto é a ocasião única e o pretexto da conexão; os indivíduos que não têm projetos e não exploram as conexões das redes estão ameaçados de uma exclusão permanente. Nessas redes, os grandes dominam os novos contratos e criam as regras para a inserção dos pequenos no mundo da interconexão. A nova forma de exclusão significa recusar-se a aceitá-las.

$\mathrm{Na}$ teoria política clássica, incorporada ao inconsciente coletivo das sociedades, o espaço público era equivalente ao espaço da liberdade dos cidadãos, no qual estes exerciam sua capacidade de participação crítica na gestão dos assuntos comuns, sob o princípio da deliberação; um espaço que se opunha, portanto, ao espaço privado regido pela dominação do poder. Hoje, as corporações apropriaram-se do espaço pú-

2 Partindo-se dos conceitos de Antonio Gramsci e Giovanni Arrighi (definido em ARRIGHI, 1996), entendese aqui por hegemonia a liderança associada à capacidade do grupo dominante de se apresentar como portador de um interesse geral e ser assim percebido pelo sistema em que se insere.

3 Entendemos por dessimbolização do mundo a desconsideração dos valores morais, tradicionais, simbólicos e transcendentais em favor de valores de ordem econômica pragmática. 
blico e o transformaram em espaço publicitário; os cidadãos que o freqüentam não o fazem mais como cidadãos, mas como consumidores de produtos ou de informação. A paisagem pública urbana é agora um material midiático privado, criando desejos e tratando o cidadão como um mero consumidor. Os espaços públicos (meios de comunicação, parques, museus etc.) só conseguem se manter abertos atolados na propaganda e no patrocínio do setor privado. O universo corporativo não precisa mais se opor ao seu entorno físico e à sociedade, como acontecia com a arquitetura modernista; agora ele se apropriou do controle direto do espaço social circundante. Sociedade civil e política, e mesmo a vida privada, acabaram por ser internalizados ao sistema corporativo, que tende a substituir a própria sociedade e suas formas de regulação.

Mas esse desenvolvimento de uma extraordinária competência do agir técnico acabou correspondendo ao crescimento paralelo de nossa impotência em resolver politicamente os problemas coletivos da humanidade, tais como a desigualdade, a miséria e a degradação do meio-ambiente. Passamos de uma sociedade política a uma sociedade organizacional e tecnológica, que pretende legitimar os direitos da pessoa, passando a encarar a liberdade de maneira totalmente privada. A identidade política universalista, à qual correspondia o conceito de cidadania, diluiu-se e fragmentou-se, permitindo a proliferação de identidades coletivas não somente particulares, mas parciais e truncadas.

\section{A hegemonia do capital e as tensões com os Estados nacionais}

A partir das duas décadas finais do século XX, passou a imperar uma nova lógica global. A intensa aceleração da globalização dos mercados e a abertura dos grandes países da periferia a produtos e capitais internacionais coincidiram com a necessidade das corporações transnacionais de ampliarem seus mercados e sua produção de modo a operar com as maiores escalas e os menores custos possíveis. A manutenção da liderança tecnológica exigia geração de caixa cada vez maior para investimento em tecnologia de ponta. E as tecnologias da informação possibilitavam um fracionamento intenso da lógica de fabricação, em busca de facilidades de produção onde quer que estivessem, fossem elas proximidade dos mercados, mão-de-obra barata, flexibilidade das normas ambientais, economias fiscais ou clusters tecnológicos. O capitalismo global apossou-se por completo dos destinos da tecnologia, orientando-a exclusivamente para a criação de valor econômico. A liderança tecnológica passou basicamente a determinar os padrões gerais de acumulação. As conseqüências dessa autonomização da técnica com relação a valores éticos e normas morais definidos pela sociedade é um dos mais graves problemas com que se há de confrontar este novo século.

A hegemonia das nações e a liderança das empresas nas cadeias produtivas globais têm atualmente como fator determinante a capacidade de inovação tecnológica, sobre a qual se articula e organiza a produção mundial em busca da composição mais eficiente dos fatores de produção global: trabalho, capital, conhecimento e recursos naturais. A liderança tecnológica define a condição hegemônica dos capitais e dos Estados, porque 
é por seu intermédio que são impostos os padrões gerais de reprodução e multiplicação da acumulação pelos ganhos que provoca. Se ela puder estar combinada com a disponibilidade de força de trabalho barata e flexível e de matérias-primas estratégicas, estará completada uma condição central para o exercício da hegemonia.

Nesse novo contexto, surgem inúmeras tensões. As grandes corporações - com seu imenso poder - definem a direção dos vetores tecnológicos e a distribuição mundial da produção e os produtos a serem fabricados ou considerados objetos de desejo. Com isso, elas ficam continuamente expostas às conseqüências negativas que se podem atribuir a esse enorme poder, a saber: responsabilidades na degradação ambiental, efeitos da utilização de transgênicos e produtos químicos na alimentação, desemprego e crescimento da informalidade, propaganda enganosa ou mentirosa. Quanto mais essas empresas gigantes crescerem e se concentrarem, mais dependerão de legitimação pública diante das agências reguladoras, dos atores da sociedade civil e dos serviços de proteção ao consumidor para manterem seu espaço mercadológico e sua margem de lucro.

Outra grave tensão ocorre entre a economia global e os Estados nacionais. O campo do capital (empresas isoladas, fluxos financeiros, organizações supranacionais - FMI, OMC, Banco Mundial) é muito forte e joga seu poder contra os Estados. Por outro lado, o capital alia-se freqüentemente com seus Estados nacionais de origem, buscando seu apoio para estender sua influência mundo afora. Contemporaneamente, essa aliança está mais forte do que nunca nos países centrais em seus acordos comerciais e nas suas diretivas ou pressões sobre as instituições internacionais. Isso não impede, porém, que até uma nação hegemônica como a norte-americana encontre-se, de repente, com um imenso déficit comercial presenteado ao país pela estratégia autônoma de fragmentação global da produção que suas grandes corporações adotaram para minimizar seus custos e melhorar seus lucros.

O principal instrumento de poder das corporações transnacionais e do capital global é a capacidade de dizer não: saio, não entro, não fico mais. Essa decisão constitui-se num ato político por excelência e basta para originar imensos traumas. O critério de dizer sim segue um padrão: orientação neoliberal do governo, tamanho relativo e ritmo de crescimento das dívidas interna e externa, ortodoxia monetária e fiscal, entre outros. O metapoder da economia mundial face aos Estados nacionais consiste, pois, na opção-saída. Os atores da economia global são extremamente eficazes e flexíveis no exercício desse poder, operando com sanções e recompensas. O poder de não investir é brandido como uma imensa ameaça. O que sanciona esse poder é o princípio da não alternativa. A economia neoliberal é o que há disponível para aqueles que quiserem fazer parte do mundo global. No entanto, a vulnerabilidade desse imenso poder reside na sua legitimação social, já que ele é extensivo, difuso e não autorizado, não dispondo de legitimidade própria. Por essa razão, Ulrich Beck (2003a; 2003b) acredita que ele fica vulnerável à violência, ao mesmo tempo em que depende dela. É preciso lembrar que poder e violência têm naturezas diferentes. A utilização continuada das formas de ameaça e sanção por parte dos capitais e investimentos globais abre espaço para crises de legitimidade do próprio capital. No longo prazo, o poder não pode prescindir de 
legitimidade; sua estabilidade repousa, em grande parte, sobre a evidência da aprovação social; caso contrário, ela gera violência e anarquia. Daí decorre - ao menos nos países de tradição ocidental - o papel essencial das instituições democráticas, que não se constitui na legitimação geral do poder e da dominação dos mais fortes, mas na obtenção de um consenso que sancione o exercício do poder e da dominação em benefício de uma governança que seja entendida como socialmente benéfica.

\section{A legitimação do capital e a responsabilidade social das empresas}

A globalização econômica permite aos atores econômicos novos recursos de legitimação. Para maximizar seu poder, eles necessitam reforçar as conexões entre capital e direito, e entre capital e Estado, o que lhes têm sido bem suprido pelo neoliberalismo de Estado. A importância crescente dos processos de arbitragem internacional faz supor o surgimento de um direito transnacional que vai se constituindo independente das legislações nacionais ou internacionais, uma espécie de lei global sem os Estados.

Os acordos fazem os contratos dependerem de instâncias de arbitragem independentes dos Estados nacionais. A desestatização da legitimidade passa pela criação de um direito autônomo, transnacional, cuja função é permitir a legitimação legal - e não social ou política - do capital.

Duas formas mais recentes de legitimação social surgiram como estratégias corporativas baseadas na acentuação dos danos causados por suas políticas globais: a responsabilidade social e, mais recentemente, a responsabilidade ambiental das empresas. A primeira é uma inteligente transformação mimética da filantropia aos tempos atuais. Nicolas Guilhot lembra que o conceito de filantropia nasceu nos Estados Unidos, ao final do século XIX, como um conjunto de obras de caridade visando atenuar o tumulto causado pela industrialização e urbanização rápidas, agravado pela incapacidade das instituições existentes em atender aos pobres. Ela tentava aplicar na gestão dos problemas sociais os métodos racionais que começavam a ser utilizados na organização industrial do trabalho, inspirados em ideólogos da época como Andrew Carnegie e Herbert Spencer. Essa situação, associada a eventuais "sentimentos de culpa" diante do quadro social vigente, pode ter levado a que uma parte dessas fortunas colossais se destinasse a fundações filantrópicas. Joseph Schumpeter, com uma frase lapidar, colocou a filantropia na lógica da maximização do retorno do investimento:

"O homem cujo espirito está todo absorvido na luta pelo sucesso dos negócios tem, como regra geral, muito pouca energia para consagrar-se seriamente a qualquer outra atividade. Para ele, um pouco de filantropia e um pouco de colecionismo mais ou menos explícitos fazem geralmente parte do negócio". (apud GUILHOT, 2004)

A renovação mais recente da face da filantropia veio por meio de um novo discurso cívico que pretende dar respostas às graves questões sociais surgidas junto com a globalização, uma espécie de "regulação moral" do capitalismo global. Esse verdadeiro marketing defensivo se auto-intitulou responsabilidade social das empresas. O recuo das políticas públicas, o desejo dos governos de empurrar para o âmbito privado as responsabilidades e os destinos da desigualdade, e a admissão de esgotamento dos 
Estados nacionais em sua missão de mediar - pelo exercício da política - as crescentes tensões sociais fruto dos efeitos negativos do capitalismo global, levaram as grandes corporações a descobrirem que esse novo espaço pode render altos dividendos de imagem pública e social. A nova filantropia se adapta com vantagens às formas de lucro empresarial, promovendo a imagem das empresas, agregando valor a suas marcas.

O mesmo ocorre em relação à degradação ambiental. Um dos maiores impasses contemporâneos é a crise ecológica global; ela pode subverter as condições de habitabilidade do planeta e impor uma recessão severa à atividade econômica, enfraquecer as atividades produtivas, agravar dramas sociais e fragilizar a espécie humana justo no momento em que suas necessidades aumentam em função do crescimento demográfico e da extensão planetária do modelo ocidental de sociedade de consumo. Tudo se passa como se a natureza opusesse uma recusa não negociável ao frenesi da lógica capitalista global. A natureza reage com perturbações climáticas com conseqüências humanas imprevisíveis, exaustão de combustíveis fósseis, rarefação e contaminação das fontes de renovação da vida e da água, acúmulo de poluição e moléculas químicas e dejetos tóxicos prejudiciais à saúde, diminuição da fertilidade das terras, dos rios e dos oceanos que nutrem a terra. Essa crise é conseqüência direta de nossos comportamentos e modos de produção e consumo.

Schumpeter definiu a evolução tecnológica como o motor indutor de um permanente impulso para frente no capitalismo. Segundo ele, simultaneamente, as tecnologias destroem e criam, estabelecendo-se uma força de destruição criativa ${ }^{4}$ na economia, cada nova tecnologia destruindo o valor das anteriores visando ampliá-lo. A acumulação seria a conseqüência desse processo, que garante o constante crescimento econômico. O papel da ciência nessa dinâmica capitalista é de promover um permanente estado de inovação, sucateando e substituindo produtos e criando novos hábitos de consumo. Dentro dessa lógica, o capital transformou a pesquisa tecnológica em área privada associada à grande corporação, visando permitir a ela realizar um monopólio do novo conhecimento - ainda que temporário - que lhe proporcione um rendimento exclusivo. Com investimentos em inovações e campanhas publicitárias de alto custo, o objetivo é chegar, antes dos concorrentes, a produtos inovadores. Marketing e propaganda criam objetos e serviços de desejo, manipulando valores simbólicos, estéticos e sociais. A inovação tenta tornar obsoletos os produtos existentes, e conferir à nova mercadoria um valor incomparável e imensurável, porque sua posse transforma-se na realização de um desejo quase mítico. São casos típicos recentes a conversão de TVs comuns em telas de plasma e o contínuo sucateamento de telefones celulares e computadores.

Passa, assim, a ser uma contingência da própria lógica capitalista a alternância de ciclos de escassez com os de abundância, quando esses produtos desejados tornam-se

4 Joseph Schumpeter via o capitalismo como um processo sempre em evolução, impulsionado pelo avanço tecnológico, destruindo e gerando continuamente novos bens e serviços e novas formas de organização industrial. Para Schumpeter, a concorrência conduz ao processo de inovação que, por sua vez, provoca a destruição das antigas estruturas. 
consumo de massa. Para que a engrenagem da acumulação funcione, assiste-se a um sucateamento contínuo de produtos em escala global, gerando imenso desperdício de matérias-primas e recursos naturais ao custo imenso de degradação contínua do meio ambiente e de falta de energia. Estruturado da forma atual, o sistema de produção industrial funciona como uma máquina que engole maciçamente recursos não renováveis, expelindo resíduos, gases e moléculas químicas tóxicas.

As propostas das grandes corporações globais para lidar com o imenso desafio ambiental também começam a surgir. Mas, na mesma linha da responsabilidade social da empresa, a tendência é para ações cosméticas e mercadológicas (empresas verdes, reciclagem de embalagens, pequenas ações ambientais etc.). No entanto, as ações compatíveis com a escala e gravidade do problema exigiriam modificações profundas no modelo produtivo dominante e nos seus modos de fabricação; ou seja, na própria lógica do sistema capitalista global. Para enfatizar a contradição entre retórica e prática, basta lembrar recente declaração do presidente de uma das maiores fabricantes de veículos do mundo afirmando que só sobreviverão as corporações que fabricarem carros de até US\$ 3.000; ou seja, o modelo de eficiência do setor ainda é abarrotar o mundo de pequenos veículos individuais consumindo imensas quantidades de matérias-primas e agravando a poluição ambiental.

David Herderson - que já foi o principal economista da OCDE - analisa a onda de responsabilidade social empresarial por outro ângulo. Afirma que esses novos compromissos corporativos são um mero expediente para encobrir o legítimo e crescente interesse pelo lucro. Ele não só duvidava que ela esteja trazendo algum benefício social, como achava que pode estar causando danos reais ao próprio sistema capitalista. Acusa os seus partidários de agirem de boa fé, mas não entenderem como o capitalismo funciona. Lembra que a boa cidadania empresarial não é gratuita, e que seu custo adicional acaba sendo pago por toda a sociedade via aumento de preços. Herderson afirma, ainda, que não ocorre nenhum avanço para a democracia quando as políticas públicas são privatizadas e os conselhos de administração das empresas assumem para si metas sociais, ambientais e econômicas conflitantes; para ele, essas tarefas cabem aos governos, que devem permanecer competentes para desempenhá-las, definindo normas de interesse social e operando sistemas de regulação (DUPAS, 2003).

\section{Conclusão}

Em síntese, o exercício de uma ética empresarial baseada na responsabilidade social e ambiental das empresas liga-se, ainda que de maneira subliminar, à substituição da idéia de deliberação participativa sobre os bens públicos - que deve ser praticada pela democracia, pela política e por suas instituições - pela noção de gestão eficaz de recursos sociais e prevenção de riscos decidida aleatoriamente pelo setor privado. Nesse sentido, essas práticas privadas diluem as referências públicas e políticas na tentativa de redução das injustiças sociais e agravos ambientais. Embora a nova tendência de responsabilidade social das empresas tenha a pretensão de aparecer como solução para as questões de exclusão social e degradação do meio ambiente, ela é - além de inócua 
diante da escala do problema - basicamente despolitizadora da questão social, pois pressupõe a desqualificação do poder público e da sociedade civil e, portanto, desconhece a possibilidade aberta pelo conflito interno no terreno das próprias políticas públicas para criar compromisso e qualidade diante dos cidadãos.

\section{Referências}

ARRIGHI, Giovanni. O longo século XX. Rio de Janeiro: Contraponto, 1996.

BECK, Ulrich. Pouvoir et contre-pouvoir à l'ère de la mondialisation. Paris: Éditions Flammarion, 2003a. ."A questão da legitimidade". Revista Humboldt, $\mathrm{n}^{\circ}$ 87. São Paulo: Goethe Institut, 2003b.

DUPAS, Gilberto. Ética e poder na sociedade da informação. $2^{\mathrm{a}}$ ed. revista e ampliada. São Paulo: Editora Unesp, 2001. Tensões contemporâneas entre o público e o privado. São Paulo: Paz e Terra, 2003.

. Atores e poderes na nova ordem global. São Paulo: Unesp, 2005.

. 0 mito do progresso. São Paulo: Unesp, 2006.

. "A questão ambiental e o futuro da humanidade". Revista Política Externa, vol. 16, nº1. São Paulo: Editora Paz e Terra, junho-agosto de 2007.

GUILHOT, Nicolas. Financiers, philanthropers: vocation éthiques et reproduction du capital à Wall Street depuis 1970. Paris: Èditons Raison d'Agir, 2004.

SCHUMPETER, Joseph. Teoria do desenvolvimento econômico. São Paulo: Abril Cultural, 1982. 